\title{
Normotensive HELLP syndrome in the midst of Dengue fever
}

\author{
Robin George Manappallil'1, Sithara Surendran², Anoop Kumar³, Ganga Prasad ${ }^{4}$ \\ Consultant, ${ }^{1}$ Department of Internal Medicine, and ${ }^{2}$ Obstetrics and Gynaecology, ${ }^{3}$ Consultant and Chief, Department of \\ Critical Care Medicine, ${ }^{4}$ Consultant and Deputy Chief, Department of Critical Care Medicine, Baby Memorial Hospital, \\ Calicut, Kerala, India
}

HELLP syndrome is a life threatening complication of pregnancy, characterized by haemolysis, elevated liver enzymes and low platelet counts. Preeclampsia is a risk factor for developing HELLP. However, some patients can have HELLP in the absence of elevated blood pressure. Dengue fever is a mosquito-borne viral infection characterized by fever, leucopenia and thrombocytopenia, and bleeding manifestations. This is a case of a young primigravida who presented with dengue fever and was found to have an associated normotensive HELLP syndrome.

\section{Access this article online}

Website:

http://nepjol.info/index.php/AJMS

DOI: 10.3126/ajms.v9i2.18764

E-ISSN: 2091-0576

P-ISSN: 2467-9100

Key words: HELLP syndrome, Dengue fever, Preeclampsia, Thrombocytopenia

\section{INTRODUCTION}

The acronym HELLP describes a syndrome consisting of haemolysis $(\mathrm{H})$, elevated liver enzymes (EL) and low platelet count (LP). The condition, first described by Louis Weinstein in 1982, is rather uncommon; seen in about 0.5 to $0.9 \%$ of all pregnancies. It is regarded as a serious complication carrying high maternal mortality and morbidity. About $10 \%$ to $20 \%$ women with severe preeclampsia can develop HELLP. ${ }^{1-3}$ However, hypertension and proteinuria may be absent in 10 to $20 \%$ cases of HELLP. ${ }^{4}$ Dengue fever (DF) is a rapidly increasing viral infection transmitted by Aedes aegypti mosquito. According to the WHO, DF is an acute febrile illness of 2 to 7 days duration in the presence of two or more of the following features: headache, retro-orbital pain, myalgia/arthralgia, rash, haemorrhagic manifestation and leucopenia. ${ }^{5}$

\section{CASE REPORT}

A 20 year old primigravida at 36 weeks gestation presented with history of fever and mild abdominal pain. Fever was high grade lasting for 2 days, leaving her afebrile for next 3 days. There was no history of preeclampsia.
On presentation, she was conscious, oriented and afebrile; moderately nourished. Her vitals and systemic examinations were normal. Her blood investigations showed haemoglobin $12.7 \mathrm{~g} / \mathrm{dL}$, total count 3,900/cumm, platelets 40,000/cumm; deranged liver functions with total serum bilirubin $1.7 \mathrm{mg} / \mathrm{dL}$, direct bilirubin $0.5 \mathrm{mg} / \mathrm{dL}$, AST 142 IU/L and ALT 63 IU/L, albumin $1.7 \mathrm{~g} / \mathrm{dL}$; and prolonged apTT (test 56 seconds, control 23 seconds). Renal functions, electrolytes, PT/INR, uric acid, TSH and corrected calcium were normal. Dengue NS1 antigen and IgM ELISA were reactive. Malarial smear, Weil Felix, leptospirosis serology and viral markers (HBsAg, anti HCV, HIV) were negative. Urine microscopy showed albumin 4+ and 10 to $15 \mathrm{RBC} / \mathrm{HPF}$. She suddenly went into labour within 6 hours of admission. Her repeat platelet count, prior to labour, was $8000 /$ cumm. Platelet and fresh frozen plasma (FFP) transfusions were given. She had a normal vaginal delivery with baby boy weighing $3.2 \mathrm{~kg}$. While suturing her episiotomy incision, she had an episode of generalised tonic clonic seizure lasting less than 1 minute with tongue bite. She was given intravenous lorazepam and magnesium sulphate. Her blood pressure continued to be 110/80 $\mathrm{mmHg}$ and blood sugars were $120 \mathrm{mg} / \mathrm{dL}$. Post ictal confusion lasted for about 15 minutes. She was started 
on intravenous fosphenytoin. MRI brain was normal. Soon after delivery, her haemoglobin dropped to $5.6 \mathrm{~g} / \mathrm{dL}$ and platelet count increased to $34,000 /$ cumm. Serum LDH was $610 \mathrm{IU} / \mathrm{L}$. Her liver functions remained unchanged. Peripheral smear was suggestive of microangiopathic haemolytic anaemia. Blood cultures were sterile. She was given packed cell transfusions following which haemoglobin became $9.6 \mathrm{~g} / \mathrm{dL}$. About 12 hours following delivery, her platelet counts increased to $64,000 /$ cumm. There was no further drop in haemoglobin, and platelets showed a steady rise to $150,000 / \mathrm{cumm}$. She was discharged in stable condition on day 8 of admission, with normal complete blood count, liver functions and urine albumin.

\section{DISCUSSION}

HELLP syndrome is characterised by preeclampsia, hepatic endothelial disruption, platelet activation, aggregation and consumption; resulting in microangiopathic haemolysis, ischemia and hepatocyte death. Complete HELLP requires the presence of all 3 components of the triad which consists of haemolysis, elevated liver enzymes and low platelet count; while partial or incomplete HELLP consists of only 1 or 2 components. In about $70 \%$ of cases, HELLP develops between 27 and 37 gestational weeks; while 10\% to $20 \%$ occur before 27 and beyond 37 weeks. ${ }^{6,7}$ During post-partum period, HELLP may develop in women who have had proteinuria and hypertension prior to delivery; and is usually seen within the first 48 hours. About $50 \%$ cases may have excessive weight gain and generalized oedema as a preceding event. These patients present with right upper abdominal or epigastric colicky pain, nausea and vomiting. Headache, visual disturbances and malaise are other reported symptoms. ${ }^{4}$ The diagnostic criteria according to Tennessee Classification System consists of platelet count $<100,000 /$ cumm, AST $>70 \mathrm{IU} / \mathrm{L}$ and LDH $>600 \mathrm{IU} / \mathrm{L}$, and haemolysis on peripheral smear. The management is based on the weeks of gestation:

- 34 weeks or later - Immediate delivery

- 27 to 34 weeks - Delivery within 48 hours after evaluation and stabilization of maternal condition; and steroid treatment for fetal lung maturity

- Before 27 weeks - Termination of pregnancy should be strongly considered.

DF comprises of 3 phases. The initial febrile phase is characterized by fever, headache, myalgia and leucopenia; and lasts for 2 to 7 days. This is followed by the critical phase, where patients become afebrile and have thrombocytopenia, increase in haematocrit levels and capillary permeability. Haemorrhagic manifestations, hepatitis, myocarditis and encephalitis may also be seen. This phase lasts for 24 to 48 hours, following which these patients enter the recovery phase. There is a gradual resorption of fluid from the extracellular compartment, with platelet counts showing a rising trend and normalising haematocrit levels. Virus isolation, nucleic acid or antigen detection (NS1) is used for diagnosis during the early stages of the disease; while serology (IgM capture ELISA) is done at the end of the acute phase. Home therapies include adequate bed rest, fluid intake and paracetamol. Intravenous fluid resuscitation and platelet transfusions are administered in hospitalised patients. Prophylactic platelet transfusion may be given at level $<10,000 /$ cumm even in absence of bleeding manifestations. Red cell and platelet transfusions may be needed in case of systemic bleeding. Transfusions with FFP or cryoprecipitate are needed in case of coagulopathy with bleeding. ${ }^{5}$

Our patient was a normotensive primigravida at 36 weeks gestation. She presented with history of fever and was diagnosed to have DF with thrombocytopenia and deranged liver functions. Haemolytic anaemia has been reported in DF. However, the presence of proteinuria, seizure episode and the rapid fall followed by increase of platelet counts were suggestive of an associated normotensive HELLP syndrome.

\section{CONCLUSION}

DF and HELLP can have overlapping features, which can be misleading. In this case, patient presented with DF but had an associated HELLP in the absence of an elevated blood pressure. This case, therefore, highlights the consideration of HELLP in all normotensive pregnancies presenting with thrombocytopenia and deranged liver functions, even in the presence of an infection.

\section{REFERENCES}

1. Weinstein L. Syndrome of hemolysis, elevated liver enzymes, and low platelet count: a severe consequence of hypertension in pregnancy. Am J Obstet Gynecol 2005; 193:859.

2. Geary M. The HELLP syndrome. Br J Obstet Gynaecol 1997; 104:887-891.

3. Karumanchi SA, Maynard SE, Stillman IE, Epstein FH and Sukhatme VP. Preeclampsia: a renal perspective. Kidney Int 2005; 67:2101-2113.

4. Sibai BM. Diagnosis, controversies, and management of the syndrome of hemolysis, elevated liver enzymes, and low platelet count. Obstet Gynecol 2004; 103:981-991.

5. WHO. Dengue: guidelines for diagnosis, treatment, prevention and control. New edition. Geneva: World Health Organization; 2009.

6. Magann EF and Martin JN. Twelve steps to optimal management of HELLP syndrome. Clin Obstet Gynecol 1999; 42: 532-550.

7. Sibai BM, Ramadan MK, Usta I, Salama M, Mercer BM and Friedman SA. Maternal morbidity and mortality in 442 
pregnancies with hemolysis, elevated liver enzymes, and low platelets (HELLP syndrome) Am J Obstet Gynecol 1993; 169:1000-1006.
8. Kulkarni D and Sharma B. Dengue fever-induced cold-agglutinin syndrome. Therapeutic Advances in Infectious Disease 2014; 2(3-4):97-99

\section{Authors Contribution:}

RGM- Concept and design of case report, reviewed the literature, manuscript preparation and treating Physician; SS- Reviewed the literature and treating Obstetrician; AK- Critical revision of manuscript and treating Intensivist; GP-Critical revision of manuscript and treating Intensivist.

Orcid ID:

Dr. Robin George Manappallil - (D) http://orcid.org/0000-0003-3973-6800

Source of Support: Nil, Conflict of Interest: None declared. 